\title{
ELEMENTOS PARA UNA ANTROPOLOGÍA DEL DOLOR: EL APORTE DE DAVID LE BRETON
}

\author{
Reinaldo Bustos Domínguez \\ Magíster en Sociología U.C. \\ Doctor en Salud Pública-Bioética
}

Correspondencia : Dr. Reinaldo Bustos Domínguez. La Concepción 81, Of. 218. Santiago. Chile 



\title{
ELEMENTOS PARA UNA ANTROPOLOGÍA DEL DOLOR: EL APORTE DE DAVID LE BRETON ${ }^{i}$
}

\author{
Reinaldo Bustos Domínguez
}

\section{Resumen}

En este artículo se recoge el aporte de David Le Breton a la antropología del dolor, a través del cual se puede comprender la necesidad de una práctica ampliada de la medicina, que a menudo se remite a una aproximación empírica y positivista, conducente a una intervención sobre las enfermedades concebidas sólo como realidades biológicas puras. Por el contrario, el análisis antropológico del dolor nos lleva a la consideración de la enfermedad no sólo como una configuración de signos clínicos, sino que como un síndrome de experiencias vividas, cargadas de significaciones, interpretaciones y explicaciones, mediatizadas por la cultura y la subjetividad individual.

PALABRAS-CLAVE: Cuerpo, Dolor, Antropología,Cultura.

\section{Resumo}

Neste artigo recorre-se a contribuição de David Le Breton à antropologia da dor através do qual pode-se compreender a necessidade de uma prática ampliada da medicina, já que a aproximação empírica e positivista vigente conduz a uma intervenção sobre as enfermidades construída somente sobre realidades biológicas puras. Do contrário, a análise antropológica da dor nos leva a considerar a enfermidade não só com sua caracterização de sinais clínicos, mas igualmente como uma síndrome de experiências vividas, carregadas de significações, interpretações e explicações mediadas pela cultura e subjetividades individuais.

Le Breton, D. "Anthropologie de la doleur". Métailié, Paris, 1995. 


\begin{abstract}
The paper presents David Le Breton's contribution to the anthropology of pain, as a proposal for a better understanding of the necessity of a more comprehensive medical practice, since more often than not, it is restricted to an empirical and positivist approach leading to intervene on diseases as if they were mere biological realities. On the contrary, the anthropological analysis of pain takes us to consider illness not only as the characterization of clinical signs, but also as a syndrome of lived experiences, loaded with significance, interpretations and explanations influenced by culture and personal subjectivity.
\end{abstract}

KEY-WORDS: Body, Pain, Anthropology, Culture.

\section{Résumé}

Dans ce texte on expose la contribution de David Le Breton à l'antrhopologie de la douleur, laquelle permet comprendre le besoin d'une pratique médicale élargie; souvent on comprend celle-ci dans une perspective empirique et positiviste ce qui conduit à une intervention sur les maladies conçues seulement comme réalités biologigues pures. Au contraire, l'analyse anthropologique de la doleur nous conduit à considérer la maladie non seulement comme une configuration de signes cliniques mais aussi comme un syndrome d' expériences vécues, chargées de significations, interprétations et explications interprétées à l'aide de la culture et de la subjectivité individualle.

MOTS CLÉS: Corps; Douleur; Anthropologie; Culture. 


\section{Introducción}

En un par de trabajos clásicos de sociología médica, Zborowski ${ }^{i i}$ en 1952 y Zola ${ }^{\text {iii }}$ en 1966 mostraron la influencia de la cultura en la percepción y manifestación del dolor. El primero, en una encuesta con sujetos sanos y enfermos de origen italiano, judío, irlandés y americano de "viejo cuño", demostró que los italianos y los judíos provenientes de Europa del Este tenían reacciones próximas frente al dolor, marcadas por una sensibilidad excesiva y tendencia a la emotividad y la dramatización. En los judíos particularmente, el dolor de uno de sus miembros hace participar a toda su familia, ya que no soportan el aislamiento o la impersonalidad de las relaciones. El dolor es percibido como un signo nefasto, que provoca ansiedad y miedo del futuro, congruente con la historia dolorosa y trágica del pueblo judío. Los italianos, por su parte, viven el dolor con la inmediatez de la queja, con analgésicos se tranquilizan y esperan. Los judíos, en cambio, desconfían y a menudo son críticos de los cuidados médicos. Los americanos de "viejo cuño" viven con desdén su dolor, que sólo molesta a los otros. Los irlandeses de confesión católica se parecen a los americanos. Unos y otros, testimonian una misma capacidad de resistencia: el dolor es más una molestia que un síntoma.

Zola posteriormente, muestra lo mismo: los pacientes italianos, ante igual diagnóstico, dramatizan más su dolor que los irlandeses. Estos últimos viven su dolor en congruencia con el sentimiento de que la vida es dura y difícil, revelando con claridad la pregnacia de los valores culturales en la vivencia de la enfermedad.

ii Zborowski, M. "Reponses culturelles au doleur" en Sociologie Médicale”. Steuder, F. Paris, Armand Colin, 1952.

iii Zola, I.K. "Culture and symptoms. An anlysis of patiens' presenting complainsts" American Sociological Rewiew, N³1, 1966
Estos ejemplos paradigmáticos nos sirven como introducción para afirmar que la experiencia del dolor siempre es singulariv ${ }^{\text {iv }}$ nadie reacciona frente al dolor de la misma forma. Cada individuo responde de una manera diferente a una herida o a una afección, aunque éstas sean idénticas. El umbral de sensibilidad es diferente. La anatomía o fisiología no son suficientes para explicar las diferencias o variaciones culturales, sociales, personales o de circunstancias que afectan a un individuo con ocasión de un acontecimiento doloroso. Y ello es porque la actitud frente al dolor no es una cosa meramente mecánica o fisiológica sino que está mediatizada por la cultura, las variaciones personales y la significación subjetiva atribuida a su presencia. El dolor es el producto de un contexto, es la expresión de una educación social. El personal de servicio en las unidades de cuidados paliativos saben que una palabra amiga o su presencia en la cabecera del enfermo suelen ser los antiálgicos más eficaces, aunque no suficientes.

En la tradición aristotélica (Ética a Nicómaco), el dolor era concebido como una forma particular de la emoción; era la medida del hombre tocado en lo más profundo de su intimidad. En los orígenes de la modernidad, Descartes concibe el dolor como mero disfuncionamiento de la mecánica corporal. La física corporal o la biología tendrán desde entonces el privilegio del estudio de los mecanismos del influjo doloroso, para describirlo con la objetividad que se requiere para la comprensión de sus orígenes, su recorrido, su punto de llegada. La psicología o la filosofía ocupan de ahí en adelante un lugar secundario, restringidas tan sólo a la anécdota de la subjetividad vivida del dolor. Desde Aristóteles hasta Descartes, para Le Breton, se inscribe una primera historia de transmutación del dolor, desde una forma de la emoción íntima a una concepción mecá-

iv Cf Le Breton, D. "Anthropologie de la doleur". Métailié, Paris, 1995. 
nica, donde el dolor es la expresión pura y simple de una mecánica neuronal y cerebral, un hecho puramente sensorial que concierne a un conjunto de fibras nerviosas que llevan hasta el cerebro un estímulo que se procesará en el centro del dolor; el hombre, con toda la complejidad de su historia personal, no tiene nada que decir. Para nuestro autor, sólo después de Los Estudios sobre la Histeria, donde Freud y Breur develan la lógica del inconsciente, se abre una primera brecha en esta interpretación mecánica de los hechos corporales, para hacer comprender que el hombre no es un mero apéndice de una actividad autónoma de la actividad neuronal. Se inicia entonces una segunda historia del dolor, donde la dimensión afectiva empieza a ser considerada.

De hecho, la investigación contemporánea, producto de la colaboración entre médicos y científicos sociales, hace justicia a la complejidad del fenómeno doloroso mostrando que entre el estímulo que lo provoca y el dolor experimentado existen numerosos filtros, que disminuyen o acentúan su intensidad. El calor, el frío, los masajes, enlentecen, amortiguan o aceleran su pasaje. Ciertas condiciones lo inhiben, como la relajación o la diversión; lo aumentan o lo difunden, como el miedo o la fatiga. Por lo tanto, no hay dolor sin comprometer la relación del hombre con su entorno, es decir, sin una significación afectiva que traduce el deslizamiento de un fenómeno fisiológico al corazón de la conciencia moral del individuo. El dolor vivido no es jamás una pura experiencia sensorial, sino más bien una percepción compleja, una manifestación que se integra a la experiencia acumulada de vida de un individuo y, en este sentido, simultáneamente sentida, evaluada e integrada en términos de significación y valor. El dolor, como experiencia humana, no es un simple hecho de la naturaleza, sino más bien una experiencia altamente simbólica, un hecho de la cultura. Pensemos en todos aquellos sujetos privados de su condición de sentir los estímulos dolorosos, expuestos a todos los peligros ambientales: los leprosos, por ejemplo. La función de defensa del dolor está ausente en ellos. Pero el fenómeno doloroso, para Le Breton, no se agota en esta función defensiva del individuo frente a los peligros del medio ambiente. Él se inscribe en una presencia mucho mas compleja, más desconcertante, imposible de recoger en una fórmula simplista. Entre el dolor concebido como una herramienta virtual al servicio de la defensa del individuo y éste, se inscribe el dolor con toda la ambivalencia y la complejidad que caracteriza la relación del hombre con su mundo. ¿Reacción de defensa? ¿Contra quién? ¿Contra qué?, se pregunta René Leriche $^{v}$, y con razón. No todas las enfermedades comienzan con dolor y muchas veces el dolor es la enfermedad.

\section{Antroposemiología del dolor}

La clínica médica y la literatura son fuentes inagotables que nos nutren de la experiencia del dolor sentido y el dolor sufrido. Un médico fránces, René Leriche, definió clásicamente la salud como "el silencio de los órganos". En realidad, el hombre sano se vive en una armónica unidad física-mental, confiado de sus recursos, y por completo olvidado de sus raíces físicas, en un equilibrio natural que no impone ningún obstáculo entre sus proyectos y el mundo circundante. El cuerpo no le pesa, más bien, se le hace cotidianamente invisible. Cuando aparece el dolor, el cuerpo se hace extraño: la lesión, el daño de una función, se imponen penosamente a la conciencia del individuo, decrece todo interés por los otros, el individuo se repliega. Una paciente nuestra, afectada de una Mielitis Transversa, refiere que cuando su dolor perianal se hace particularmente agudo, pierde el apetito, el gusto por vivir, se hace más susceptible, apática, no puede dormir. Su dolor la induce a una renuncia par-

Cit. por Le Breton. 
cial de sí misma, amenaza su identidad, la obliga a recluirse solitaria, para evitar arriesgar perder su autoestima frente a los otros. Todo dolor, incluso el más leve, induce una metamorfosis en el sujeto, nos revela nuestra impotencia y nuestra fragilidad, no tan sólo altera la relación del hombre con su cuerpo, sino que invade más allá: contamina la relación total del hombre con su mundo.

La semiología médica nos enseña que existen dolores agudos y crónicos. El primero es transitorio, la ansiedad está generalmente ausente en tanto la mayoría de estos dolores se asocian a causas contingentes. Para el niño son experiencias formativas, que le enseñan de su vulnerabilidad ante el medio o de la fragilidad de su condición. Cuando se hacen un poco más intensos y permanentes, signos de un mal insidioso, recurrir al médico es necesario en tanto interlocutor obligado en nuestro mundo occidental, para que le ponga nombre y lo reduzca. Los dolores agudos no afectan mayormente las relaciones sociales, más bien despiertan la solidaridad y la protección de los otros. Son pequeños signos que, incluso, refuerzan el sentimiento del valor personal. Los dolores crónicos, en cambio, son una penosa carga. Van desde una sorda presencia hasta reagudizaciones variables en intensidad, que limitan toda forma de existencia. A menudo, son un límite al poder médico, en su comprensión y en su curación. Nuestra paciente aquejada de Mielitis nos dice que su dolor es una experiencia horrenda, que violenta los límites de su condición humana, inaugurando un modo de vida, prisionera de su dolor. Le Breton recuerda a Tolstoi, que en La Muerte de Iván Illitch nos muestra al protagonista atormentado por el dolor, dolor que olvida a veces o imagina alejado para siempre, pero que reaparece súbitamente para atacarlo. La ansiedad que nace de tal estado, el sentimiento de un suplicio que no terminará sino con la muerte, hace para Iván Illitch, como para nuestra paciente, aún más intolerable la experiencia.
La depresión y el dolor crónico se alimentan mutuamente. Cuando el dolor se hace total y los pacientes se sienten sumergidos en un sufrimiento que los envuelve por entero, como en el caso de las personas afectadas de cánceres o sida, la analgesia farmacológica plantea dilemas éticos importantes para el paciente, en tanto se comprometen los últimos instantes de vida y de relación con sus seres queridos. Para los médicos no es menos difícil: a menudo se plantean dudas en torno a la sub-evaluación de la intensidad del dolor, el temor a inducir cambios secundarios o producir una dependencia de los medicamentos. Pero lo común es ver pacientes terminales con dosis masivas de analgésicos que neutralizan la conciencia del sujeto para que no sufra más; pero el remedio desborda el mal, puesto que se suprime la conciencia y la vida de relación. El paciente muere en el sopor, inconsciente de sus últimas horas de vida, privado de un último contacto con sus seres queridos, alimentando así la culpabilidad de estos.

\section{La ambigüedad del dolor y su efícacia simbólica}

En psiquiatría nos confrontamos a menudo con dolores y quejas somáticas que no tienen correlación orgánica. Aquí el dolor es signo de un sufrimiento que autoriza socialmente la búsqueda de ayuda médica. Las enfermedades funcionales, con su dolor y sufrimiento, son a menudo un llamado de atención a su soledad o insignificancia. Después de Freud, y más allá de la respuesta terapéutica inmediata, el médico debe ser capaz de descifrar su mensaje. El dolor como síntoma es la pantalla donde se dibujan - en el caso de la histeria, por ejemplo- la búsqueda obstinada de amor y reconocimiento. En el hipocondriaco, se refleja la vivencia compleja de un cuerpo cruzado por las experiencias dolorosas, de las cuales el individuo es un ingenioso inventor. En la actualidad es común la presencia de individuos 
que han sufrido un accidente laboral y que persisten con dolores más allá de la convicción clínica de que no tienen nada orgánico comprometido. Son "paranoias del cuerpo", como las definió Roa. La sospecha de un trastorno psiquiátrico acentúa en ellos la idea de ser víctimas de un desprecio o de una injusticia. Ante una medicina, heredera del dualismo cartesiano que separa radicalmente cuerpo y hombre, este último vaga dividido por los diferentes servicios médicos sin que nadie lo escuche y dé respuesta a su padecimiento. La impotencia alimenta su sufrimiento, el cual se transforma en un problema de identidad, signo de una buena fe puesta en duda. Hay muchos otros ejemplos en psiquiatría que muestran con elocuencia que el dolor está siempre presente, entreverado en los vericuetos de la historia personal. Entre un mal de vida y un mal del cuerpo, oscila poniendo en relación - a veces sutilmente, en otras con crueldad y locura, como ocurre en algunos pacientes esquizofrénicos o dementes- a la carne y el espíritu. Como hemos dicho, ninguna ley fisiológica puede dar enteramente cuenta del dolor, puesto que es múltiple: garantía de una reivindicación, sustituto de amor para paliar la ausencia, modo de expiación, medio de presión, etc. En numerosos casos, el dolor cumple, evidentemente, una función de soporte de la identidad personal. Pero como también el cuerpo y el dolor no escapan a la condición de cada cosa humana, como algo construido social y culturalmente al interior de infinitas variedades, el dolor del cuerpo y el sufrimiento del hombre no escapan a la eficacia simbólica del efecto placebo, como una ilustración evidente de que la realidad corporal se enraíza en el corazón de un mundo simbólico y cultural. A la evidencia de este efecto de eficacia simbólica descrita por Marcel Mauss y Claude Levy-Strauss (recordados también en la obra monográfica de Le Breton) en las sociedades tradicionales, se agrega la constatación de que un 35\% de los pacientes declara encontrar alivio tomando placebos. Hallazgos no menos significativos cuando la evidencia empírica nos dice que sólo el $75 \%$ de los enfermos aquejados de dolores intensos se alivia con morfina. La eficacia simbólica nos recuerda entonces el carácter múltiple del dolor, que afecta al hombre más allá de su pura organicidad. Estudios que demuestran lo anterior abundan en la literatura médica. En pediatría es conocido el efecto controlador de la aprensión y el dolor de los niños sometidos a una intervención quirúrgica cuando están acompañados por sus madres, a las cuales se les ha explicado y calmado, a su vez, de su propia ansiedad. El placebo actúa entonces en el corazón del vínculo social, donde el dolor es una caja de resonancia de significaciones personales y sociales.

Pero el dolor, desde el punto de vista antropológico, no se agota en lo anterior. La rica relación entre el mal y el dolor, tan cara a toda conciencia religiosa en los relatos bíblicos, ocupa parte importante del estudio de Le Breton. No debemos ignorar que las culturas religiosas imponen su marca en los comportamientos y valores de los individuos a la manera de un inconsciente cultural. No ocurre sólo con el cristianismo, también con otras religiones en las cuales se constatan zonas de divergencias con el catolicismo: la reforma protestante rompió, por ejemplo, la noción de un dolor pleno de gracia y de virtud legitimando la lucha contra éste. A la inversa, los musulmanes no se rebelan frente a la adversidad o el sufrimiento, no se confrontan como el cristiano a la paradoja del justo sufriente. El dolor como figura del mal, que vincula enfermedad y falta, es un constante recuerdo de nuestra fragilidad humana. La modernidad no escapa a esto; el imaginario del sida nos recuerda en la actualidad lo mismo: que una carne sufriente es una carne en falta. No en vano aquellos infectados por transfusiones sanguíneas se sienten y son percibidos como "inocentes". Y es que la atribución dada por el 
hombre reviste de sentido a su dolor y le permite mantener intacta la mirada sobre las cosas, rechazar el miedo, mantener su identidad. La integración del dolor en una cultura que le da sentido y valor es para los individuos un soporte simbólico que le otorga consistencia a su capacidad de resistencia: todas las sociedades, al definir implícitamente una legitimidad para el dolor, están indicando lo esperable o lo no esperable. El dolor se construye socialmente, se ritualiza socialmente. Así se explica la variabilidad de respuestas frente al dolor, su dramatización o su interiorización: el dolor no es puramente la medida de una lesión fisiológica, tal como lo destacáramos al comienzo. La fijación del dolor en la opacidad del cuerpo puede ser incluso una defensa profesional, en que el médico no renuncia a su privilegio de especialista de descubrir el origen del dolor. Así, vemos a pacientes circular por diversos servicios médicos buscando una respuesta causal que no llega, terminando presos como objetos de una relación técnica. En el caso de dolores crónicos, ésta se instala como una ilusión compartida, que se alimenta de una obstinación recíproca en las posibilidades omnipotentes de la medicina. Pero el dolor no desaparece, pues tiene usos variados, es un material inagotable y fecundo en manos de la invención de individuos-artesanos de su dolor. Unos lo eligen para dar testimonio de su fe: el dolor es una ofrenda; para otros, no religiosos, es un signo de estatus social. Ocurre a menudo en aquellos a quienes su dolor crónico los saca de su medianía social, familiar o laboral, les da una identidad, les permite negociar con los otros. En fin, el dolor es una eficaz herramienta con muchos fines. En Vigilar y Castigar, Michel Foucault nos entrega un detallado repertorio de los usos sociales del dolor como suplicio y castigo, evidencia de sus usos múltiples.

\section{Modernidad y dolor: hacia una sociedad anestesiada}

En las épocas pre-modernas, los principios de vida y muerte eran la guía de la vida colectiva. Las divinidades eran las referencias últimas de la vida y la muerte, del dolor y sufrimiento de los hombres; en sus manos estaba el destino. Con la modernidad desaparecen las divinidades y las referencias religiosas al orden social. Los principios que guían a la sociedad emergente son aquellos de "orden y caos". En este nuevo escenario, la ciencia empieza a ocupar un lugar preponderante en la explicación de las leyes del cosmos. Después de la Revolución Francesa, la medicina hace su aparición como eficaz aliada del orden para desterrar al caos, de aquella parte del caos que implica dolor, sufrimiento y muerte. La evolución reciente de la medicina es testimonio de un desplazamiento de técnicas que se han difundido prácticamente a todas las sociedades occidentales, tratando de alcanzar este objetivo del progreso: desterrar para siempre del dolor, el sufrimiento y la muerte, vividos como ruidos insoportables del funcionamiento social $^{\text {vi }}$. En lo que atañe al dolor, coincidimos con Le Breton que dice que la medicina lo ve solamente como un anacronismo, no sólo cruel sino como un equivalente moral de una tortura. Pero la fantasía de su supresión total, por parte de la técnica médica, es otro sueño moderno que no tendría otras consecuencias que no fuera también la indiferencia por la vida.

Precisamente, el gran aporte de la antropología del dolor presentado en esta reseña de la obra de David Le Breton, es humanizar la medicina para dignificar la vida.

vi Cf. Bustos, R. "Las Enfermedades de la Medicina" Ed. Cesoc-Colegio Médico (reg. Santiago), 1998. 